Island Studies Journal, Vol. 11, No. 1, 2016, pp. 131-132

\title{
GUEST EDITORIAL INTRODUCTION
}

\section{Thematic Section: Papers from the Excellence Network of Island Territories (RETI) meetings, Orkney, Scotland, June 2015}

\author{
James E. Randall (Guest Theme Editor) \\ University of Prince Edward Island, Canada \\ jarandall@upei.ca
}

\begin{abstract}
This guest editorial introduces the thematic section of papers, earlier drafts of which had been presented at the RETI meetings held at Orkney College, University of the Highlands and Islands, Scotland, in June 2015.
\end{abstract}

Keywords: Corsica, islands, Orkney, RETI, University of the Highlands and Islands

\section{Introduction}

RETI stands for Reseau d'Excellence des Territoires Insulaires; loosely translated into English as the Excellence Network of Island Territories. RETI has existed since 2010 when a group of 19 University Presidents or their representatives met on the French island of Corsica. Member universities are located throughout our world of islands, with the greatest concentration in and around the waters of the Mediterranean and the North Atlantic. It currently includes 26 formal members. You may ask yourself, why are there so few members when there are clearly many more universities and colleges on the many world islands? Part of the answer is that this is still a very young organization. It takes time to build up an engaged network of island universities. The other answer to this question is that it takes more than being located on an island to qualify for membership. Just as there are no formal criteria for membership in the grouping of United Nations' Small Island Developing States (SIDS), RETI does not have formal admission criteria. However, there is an implicit understanding that the educational institution must play a fundamental role on the island in which it is located; not only in providing educational opportunities for islanders, but also in the economic, cultural and environmental development of that island or islands. Therefore, despite the scholarly prestige and significance of universities such as Oxford and the University of Tokyo, they do not have the same breadth and depth of relationship with, and impact on, their respective islands of Great Britain and Honshu, Japan, as would, for example, the University of the Aegean on Lesvos Island, Greece, or the University of Prince Edward Island on Prince Edward Island, Canada.

There have been at least seven meetings of the RETI group since its inception where various planning and scholarly activities have taken place, including meetings of the Governance Committee (the Presidents/Rectors/Principals or their representatives), sub-group meetings of members organizing applications for Erasmus-type academic programs and thematic summer schools. There have been four meetings over the past four years that could be described as being comprehensive in nature, consisting of the three components of a governance meeting, a short summer school and a conference where presentations on island studies themed research can be made by faculty and students from the member universities. These last four meetings took place in Lesvos, Greece (2012), Sardinia, Italy (2013), Prince Edward Island, Canada (2014) and Orkney, Scotland (2015). Although Island Studies Journal 


\section{J. E. Randall}

(ISJ) has been the official journal of RETI since 2013, and affiliates of the RETI member universities are frequent contributors to this journal, until this issue ISJ had never published a special thematic section consisting of papers from one of the RETI conferences.

\section{This thematic section}

This thematic section emerged from the RETI meetings hosted by the University of the Highlands and Islands and held in June 2015 in Kirkwall, on the Orkney island of Mainland (ironically the name of the largest island in the archipelago), to the north-east of 'mainland' Scotland. The theme of the conference and summer school was the "Impact of cultural heritage on economic development in island destinations"; but the 33 papers in the program covered a wide range of topics. Following the meetings, a call was made to the presenters to consider submitting manuscripts to a peer-review process, with the goal of publishing in ISJ.

The five papers in this special section represent the final outcome of that call. Two of the papers (Brinklow and Riquet) speak to aspects of islandness and the concept of the island as reflected in examples of literature. One (Karampela, Kizos and Spilanis) develops a model to better understand the nature of agritourism on small islands. A fourth (Alexander) explores the perceptions of youth in Orkney and Shetland in the decision to move away to pursue a university education. The fifth paper (Harling Stalker and Burnett) delves into the complex relationship between culture workers and the Scottish islands on which they practice their creative production.

There may be only tenuous connections across the five papers as measured by their subject matter; but what binds them together may be more structural and institutional than thematic. Structurally, they show that there is a high degree of scholarly quality associated with the researchers from these RETI member universities. They also show that the analysis and findings associated with research on the many topics associated with small islands have implications for subject matter across a wide range of disciplines and contexts beyond that associated with island studies and islands. As such, the section addresses a call by Stratford (2015) from her reflections on the future of Island Studies Journal. It also addresses the institutional goal of the RETI organization to create common platforms for research and educational collaboration and make islandness a collective asset. ${ }^{1}$ It is difficult to answer the hypothetical question as to whether the scholarship associated with these articles would have been made available to the public had RETI not existed. However, it is clear that RETI has facilitated this exchange and has served as a 'space of cooperation in scientific research'. ${ }^{2}$

It is my hope that RETI and ISJ will continue to collaborate in order to disseminate even more island scholarship.

\section{Reference}

Stratford, E. (2015). A critical analysis of the impact of Island Studies Journal: retrospect and prospect. Island Studies Journal 10(2), 139-162.

\footnotetext{
${ }^{1}$ From the homepage of the Reseau d'Excellence des Territoires Insulaires at the University of Corsica Pasquale Paoli, France. Retrieved from http://reti.univ-corse.fr/Aims a163.html

${ }^{2}$ From a newsletter of the Euro-Mediterranean Tourism and Water Campus. Retrieved from http://www.emta.eu/reti-in-which-the-uib-participates-organizes-two-summer-schools-on-sustainable-development-andmarine-resources-inisland-territories/
} 